\title{
Rigorous Phenomenography: A Conceptual Model
}

\author{
Dr. Jennifer M. Straub \\ Laurentian University \\ 935 Ramsey Lake Rd., \\ Sudbury, Ontario, CANADA \\ P3E 2C6 \\ E-mail: JStraub@laurentian.ca \\ Dr. Nancy Maynes (Corresponding author) \\ Nipissing University \\ North Bay, Ontario, CANADA \\ P1B 8L7 \\ Tel: 705-840-2060 E-mail: nancym@nipissingu.ca
}

Received: April 6, 2021

doi:10.5296/jse.v11i2.18496
Accepted: May 16, $2021 \quad$ Published: May 16, 2021

URL: https://doi.org/10.5296/jse.v11i2.18496

\begin{abstract}
This paper presents a visual conceptual model for the qualitative research approach referred to as phenomenography. The static and recursive stages of a rigorous phenonemographical approach to research are outlined in detail. Using the example of a research study situated in pre-service teacher education, the authors explain how the fifteen distinct steps of phenomenographic research should be addressed with attention to the sequencing of these steps to support reliability and rigor of the research process and validity and generalizability of the outcome spaces that may result from the use of phenomenography.
\end{abstract}

Keywords: phenomenography, qualitative research, methodology 


\section{Introduction}

According to Feldon and Tofel-Grehl (2018), phenomenography is a "methodological paradigm" which places emphasis on "personal conceptions as a necessary construct to understand the relationship between the physical events" that someone may experience and the "personal meaning" developed from said experiences (p. 887). As an approach it "aims to investigate the qualitatively different ways" in which individuals "understand a particular phenomenon or an aspect of the world around them" (Marton \& Pong, 2005, p. 335). It allows researchers to understand how participants conceptualize an idea and potentially to explore the factors that influence their cognitive frames to provide evidence of participants' thinking as well as changes in their thinking. Changes in a participants' thinking would require the dual (before/after treatment) use of phenomenography to uncover differences that could reasonably be attributed to identifiable experiences. Phenomenography can help researchers to identify a participants' prior knowledge, including its relative accuracy and immature conceptions about various concepts (Driver \& Easley, 1978). Phenomenography has some similarities to constructivist research as it also has the potential to lead researchers to understand and discover the nature of students' prior conceptions in order to influence curricula and develop teaching approaches. Both approaches have the goal of increasing students' ability to combine new and more complex knowledge into what they have already learned (Hughes \& Sears, 2004).

\subsection{The Range and Purpose of Phenomenographic Research}

Individuals perceive learning experiences in unique ways. Phenomenography assumes a limited number of qualitatively different ways participants can relate to conceptual understanding. It is the role of the researcher to categorize the differences found in these experiences (Åkerlind, 2005; Marton, 1992). Phenomenography does not rely on predetermined categories, but rather allows hierarchical categories to be determined by participant responses, which may allow for greater consideration of a particular topic. This is the premise researchers explore when they use phenomenography. Once the different ways participants understand a concept and how it is uncovered becomes clear, a deeper understanding of what takes place when learners are thinking about the concept will emerge. By using phenomenography as a methodology, researchers can examine how students, as a group, learn and understand in different ways.

Phenomenography is an increasingly popular research methodology to help us understand conceptual growth. This approach has been used to study the learning impact of many academic programs including, but not limited to, nursing (Sjöström \& Dahlgren, 2002), engineering (Case \& Light, 2011; Trigwell \& Yasukawa, 1999), mathematics and statistics (Reid \& Petocz, 2002), physics (Ornek, 2008; Prosser, 1994), contemporary information literacy research (Boon \& Webber, 2007; Bruce, 1999; Limberg, 2000; Maybee, 2007; Yates, Partridge, \& Bruce, 2009), second language learning (Polat, 2013), and biochemistry (Newton \& Martin, 2013). Most of these studies focused on instructional methods (see, for example, Marton et al., 2004; Trigwell, Prosser, \& Ginns, 2005).

However, much of the literature also attends to variation theory (Booth, 2008; Hella \& Wright, 2009; Lam, 2013), which is based on the idea that in order for conceptual development to be 


\section{NI Macrothink}

Journal of Studies in Education

ISSN 2162-6952

2021, Vol. 11, No. 2

facilitated it should focus on the individual's ability to experience variation in certain features of the phenomenon that might be taken for granted (Marton, Runesson, \& Tsui, 2004). More specifically, researchers have used phenomenography to uncover how learning develops during academic studies (Dahlin, 1999) in a variety of different academic fields.

For example, Newton and Martin (2013) used phenomenography to uncover the conceptions that undergraduate students held in biochemistry topics related to human metabolism. They categorized written responses into an inclusive hierarchy to identify increasing levels of accuracy and complexity of the integration of metabolism-related concepts. Then they used a second strategy where they categorized the same responses using the Structure of Observed Learning Outcomes (SOLO), which is defined as a "taxonomy of increasing connectivity and inclusiveness" (p. 79). Finally, Newton and Martin used questions from the midterm and the final exams, ranking the responses using the Biology Blooming Tool (BBT; Crowe, Dirks, \& Wenderoth, 2008) to assess the level represented in the Bloom's Taxonomy framework. Such approaches show that applications of phenomenography can be supplemented by many variants in ways to gather data, while the approach to making meaning from the data is filtered using a phenomenographic lens.

Newton and Martin (2013) found that having a clear picture of the level of learning about a phenomenon or where students should be at throughout a course with regards to understanding course concepts allows an instructor to maintain focus and direction in the creation of course content, assignments, and exam questions. The observation of a relationship between a deep learning approach and improved performance at higher levels of cognitive complexity suggests that such analytic methods may be useful to educators seeking to reward and encourage deeper learning (Newton \& Martin, 2013). Thus, phenomenography is an excellent tool to help uncover increasing levels of cognitive complexity as related to participants' understanding of a phenomenon.

\subsection{Data Collection Using a Phenomenography Approach}

Phenomenographic research is predicated on the rigorous process by which the researcher undertakes a careful plan for achieving a particular goal. Figure 1 outlines a systematic approach to uncovering the perceptions held by participants about specific phenomena. This figure has been developed through a synthesis of a variety of studies that were completed using phenomenography as the chief research strategy. 


\section{MlMacrothink}

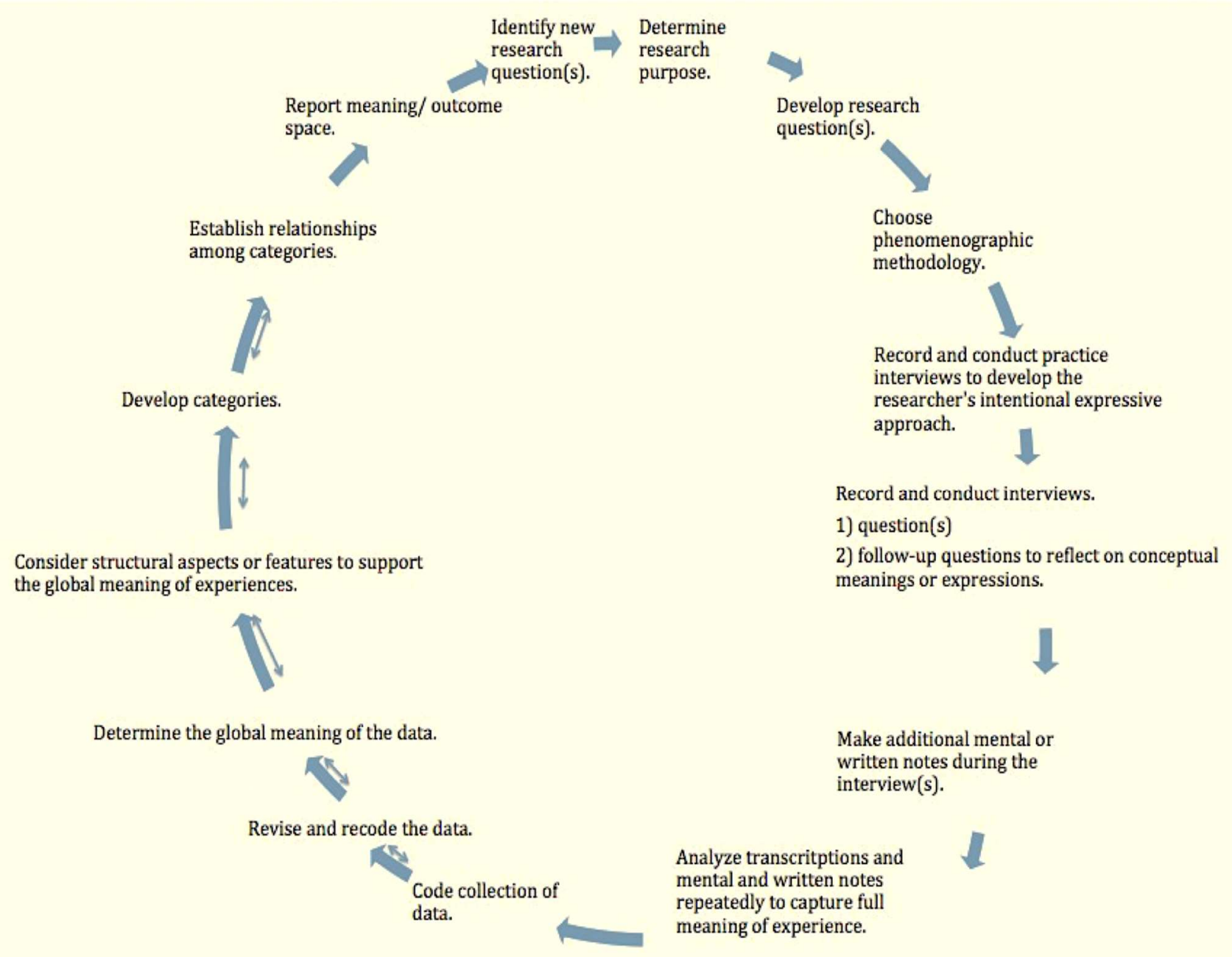

Figure 1. Phenomenography Methodology

\section{Delving Into This Model}

The items presented in Figure 1 (Straub, 2020) are adapted from phenomenography literature (see Akerlind, 2005; Entwhistle \& Marton, 1994; Goh, 2013; Gunton, Bruce, \& Stoodley, 2012; Kinnunen \& Simon, 2012; Limberg, 2000; Marton \& Booth, 1997; Marton \& Pong, 2005; Saldaña, 2008). The arrows indicate the directional path. Once the collection of data has begun, the arrows indicate the recursive path of the inquiry, where the researcher returns to the previous step to ensure that each step is clearly addressed before attending to the next step. By completing each step, the researcher is able to meet the requirements of trustworthiness and reliability with their data and its interpretation.

This model has 15 distinct steps that represent the complexity of phenomenography. While the initial seven steps of the phenomenographic process are linear and sequential, the remaining eight steps of the process are recursive. The nature of the data, the number of participants, and timeframe of data collection, the researcher's goals, the intended use of the data, and the researcher's skills will all have an impact on how recursive these final eight steps of the process 
will be as meaning is sought from the body of data. Table 1 separates the phenomenography steps into linear and recursive stages of the process, using the example of interview data as the sole data source.

Table 1. The Linear and Recursive Stages of Phenomenography

\begin{tabular}{|c|c|}
\hline Linear Stages of Phenomenography & Recursive Stages of Phenomenography \\
\hline $\begin{array}{l}\text { - Determine the research purpose } \\
\text { - Develop the research question(s) } \\
\text { - Choose phenomenographic } \\
\text { methodology } \\
\text { - Record and conduct practice } \\
\text { interviews to develop the } \\
\text { researcher's intentional expressive } \\
\text { approach } \\
\text { - Record and conduct interview(s) } \\
\text { guided by: } \\
\text { 1) question(s); and } \\
\text { 2) follow-up question(s) to reflect } \\
\quad \text { on conceptual meaning and } \\
\quad \text { expressions } \\
\text { Make additional mental or written } \\
\text { notes during the interview(s) } \\
\text { Analyze transcriptions and mental } \\
\text { and written notes repeatedly to } \\
\text { capture the full meaning of the } \\
\text { experience }\end{array}$ & $\begin{array}{l}\text { - Code the collection of data } \\
\text { - Revise and recode the data } \\
\text { - Determine the global meaning of } \\
\text { the data } \\
\text { - Consider structural aspects or } \\
\text { features to support the global } \\
\text { - } \text { meaning of experiences } \\
\text { - } \text { Establish relationships among } \\
\text { - } \text { categories } \\
\text { - } \text { Ideport meaning/outcome space }\end{array}$ \\
\hline
\end{tabular}

\subsection{Stages of Phenomenography}

In the following section, each stage of the phenomenographic approach to research, as shown in Figure 1 and Table 1 is described more thoroughly. The linear stages of phenomenography will be addressed first, followed by discussion of the recursive stages of the methodology.

\subsubsection{Determine the research purpose}

Researchers use a wide range of research approaches to investigate various phenomena. To a large extent, the methodology that is chosen for any research investigation is reflective of the questions that are being investigated in the study. From the full range of approaches that could be used (see for example, Creswell, 2009) each researcher must consider the most effective and most efficient way to acquire data that will address the research question(s), while ensuring that the data collection approach is convenient, cost effective, and most likely to provide data that will serve the purpose of collecting it. To do this, researchers must first determine the purpose of their research. This will be done by examining what is already known about the 
topic from previous research, by identifying gaps in the existing research data about the topic, and by considering who might care about or use the new data that the researcher intends to collect.

\subsubsection{Develop the research question(s)}

Research data can be messy. However, good and useful research data directly reflects the quality and clarity of the data that are collected from any study. To ensure that the researcher starts a study that will yield clear and useful data, the effective researcher must pose question(s) then anticipate the type of data that may ensue from asking the question(s). If the anticipated data has the potential to be unclear, unspecific, ambiguous, or too messy to support meaningful interpretation, the researcher needs to work on the questions to address these issues.

If dynamic approaches such as interviews are being used to collect data (as opposed to, for example, a survey which is relatively static) the researcher must also preplan follow-up probes to ask research participants so that meanings can be made clearer and deeper meaning can be uncovered as participants respond to the initial question. At this stage of a research project, researchers often introduce a small pilot project to test the effectiveness of their questions and probes and the usefulness of these questions as methods to uncover meaning in the data. Such pilot studies will not include any participants who later engage in the actual study. After a pilot study, the researcher may then choose to adjust initial questions and probes to support more effective data collection in the larger study. Pilot studies might also serve to give the researcher knowledge about effective warm-up approaches to use with participants before data collection begins. Such warm-up questions are beneficial to develop rapport with the interviewees (Goh, 2013).

\subsubsection{Choose phenomenographic methodology}

If the goal of the research study is to uncover learning as a result of experience, phenomenography may be chosen for the study's methodology. Marton's (1981) seminal work was aimed at "finding and systematizing" the different ways of understanding and explaining why individuals who experienced the same phenomena or learning situation arrived at different solutions or "understanding of experiences" (p. 177). Phenomenography as an "interpretive approach" (Goh, 2013, p. 2) allows researchers to understand how participants conceptualize an idea and has the potential to allow for enriched understanding by exploring the factors that influence participants' cognitive frames and to provide evidence of participants' thinking as well as changes in their thinking. While phenomenography will provide direction to the researcher about how to collect relevant data, there is a wide range of data collection strategies that can be used within the framework of this methodology. The key focus of selecting strategies for data collecting should be guided by the need to keep the resulting data as close as possible to the participants' lived experiences. The potential of the strategy for data collection should also be considered for:

- $\quad$ its robust nature to support uncovering deep meaning; and

- $\quad$ its potential to be used in conjunction with other methods of data collection (e. g., observation, document analysis, conceptual frame/model production, etc.) so that the 
researcher has the option to triangulate data sources and thereby enrich the reliability and validity of the data as a connected body of information.

2.1.4 Record and conduct practice interviews to develop the researcher's intentional expressive approach

According to Anderberg, Svensson, Alvegård, and Johansson (2008), the intentionalexpressive approach to research data collection "focuses on how individuals use socially and culturally constructed language when expressing their understanding in a given situation and developing knowledge" (p. 3). The researcher's choices in language use in questions and probes are also influenced by "emotions, values, aesthetics, and interpretive frameworks, conceptions, discourses" (p. 4) that make up an intentional expressive approach. In phenomenography where "expressions always have a broad spectrum of possible meanings" where "any given meaning could be expressed by different expressions" to respond to a particular context (p. 4) it is important to be consciously aware of how the "interplay between expressions, their meanings and conceptions" (p. 3) might influence the subjects' ability to share their own expression of concepts during interviews.

Conducting effective and informative interviews that uncover rich data and allow the research to uncover deep meaning is a complex research skill. Researchers should therefore develop their interview skills before they invest efforts into a full-scale study. Since the quality of the data from a study will reflect the researcher's ability to uncover the data, practice with interviewing is essential. Such practice will also help researchers to tighten the wording of their key research questions and expand their ability to consider probes that will lead to enriched data. Once again, people who participate in practice interviews should not also participate as part of the data pool in the actual study.

2.1.5 Record and conduct interview(s) guided by: 1) question(s); and 2) follow-up question(s)/probes to reflect on conceptual meaning and expressions

Selecting participants to participate in the study and who will provide data for the study is critically important for a researcher to consider. The generalizability of the study findings is directly reflective of the value of the data these participants can provide. The researcher needs to be able to make the argument that the group of participants is fairly typical of the target population to which they belong. Once a satisfactory group of participants is chosen and application research ethics approval is acquired from the relevant institution(s), the researcher can begin to collect data. Most phenomenographic research projects will involve participant interviews to uncover participant meanings. Since interviews typically result in long and detailed data sets, phenomenographic researchers will usually seek the approval of research ethics boards and individual participants, in writing, to record data collection sessions. Such recordings allow the researcher to decode the data repeatedly and to check for utterances from participants that expose emerging categories of meaning. Recording also allows the researcher to re-mine the data for examples once the study is ready to be reported and mobilized. Transcriptions of such recordings must be completed verbatim so actual words of the participants are used in the development of categories of meaning. 
In phenomenography, the questions that are asked of participants in the study must be "broad enough to obtain meaningful responses without forcing a particular structure" upon interviewees (Bruce, Buckingham, Hynd, McMahon, Roggenkamp, \& Stoodley, 2004, p. 146).

\subsubsection{Make additional mental or written notes during the interview(s)}

Researchers who use phenomenography as a methodology should also keep some form of written notes to record key ideas that arise during interviews, observations, or from document analysis. Research notes can then be used during the data analysis stage of the work to confirm, support, question, or even confound, the data that are uncovered during the interviews. Mental or written notes taken during an interview also allow the researcher to track tangential thoughts as they listen to participants' responses and to analyze utterances on-the-spot so that appropriate follow-up probes can be given to the participant. Research notes are vital and allow the researcher to uncover deeper meanings that may only be alluded to in the participant's original response. As researchers develop their notes and compare notes from initial interviews and from pilot testing, they may also use ongoing notes to refine their approach and the extent of the probes during interviews.

2.1.7 Analyze transcriptions and mental and written notes repeatedly to capture the full meaning of the experience

Recordings and written notes are commonly used, and often complimentary, methods of noting the words of participants to create a record that can be analyzed and re-analyzed as themes begin to emerge among participant responses. Recordings can preserve precise utterances that provide quotations for exemplification of key ideas during dissemination of research findings. A researcher's notes provide pathways to key thoughts and guideposts to help the researcher attend to emerging themes that may need probing for clarity. Together, the researcher's mental or written notes and transcribed recorded data provide a rich set of information to help the researcher apply phenomenographical analysis to uncover deep meaning in the data set.

\subsection{The Recursive Stages of Phenomenography}

The previous sections addressed the linear stages of phenomenography. The following eight sections will address the recursive stages of phenomenography, which largely focuses of the meaning to be found in the data and how phenomenography researchers go about data analysis to help ensure the validity and reliability of their findings.

\subsubsection{Code the collection of data}

Coding the collection of data requires the researcher to identify "thick descriptions" (Denzin, 1989). This highlights responses that are detailed in nature. Some of these may include comments that are highly emotive, significant to the subject and clearly illustrate a perspective about the subject of the study. According to Patton (2002) "the challenge of qualitative analysis lies in making sense of massive amounts of data” (p. 276). He highlights the researcher's role as "reducing the volume of raw information, sifting trivia from significance, identifying significant patterns and constructing a framework for communicating the essence" of "themes" (p. 275). Allowing participants to provide open-ended responses then permits researchers to 
use "free" and "open coding" to identify the ideas and themes that emerge, and document conceptions that present themselves (Goh, 2013, p. 4).

Researchers can use any meaningful coding practice that they have developed. For example, if the researcher was examining transcripts about a group of participants' comments about their understanding of the concept of citizenship, the researcher might uncover recurring themes about global travel as a contributor to their views about tolerance of refugee needs. When this theme emerges, the research could apply a code such as GT=tolR (Global travel is common among those who express tolerance or empathy for refugees) and would then continue to apply that code to other utterances by the same or different participants so that frequency and commonality of the theme could be identified. Phenomenographic researchers might also choose to use colour coding for recurring themes in recording transcripts. Either of these coding processes allows the phenomenographic researcher to quantify the qualitative data so that they can report on the frequency and strength of emerging themes in the data set.

\subsubsection{Revise and recode the data}

In phenomenographic research, the researcher will examine and recode the data repeatedly to capture the full meaning of the experience that was expressed by participants. Data from interviews, for example, will allow the researcher to compare and re-analyze data to obtain a more in-depth understanding of participants' behaviours and attitudes (Blummer, Watulak, \& Kenton, 2013). The researcher begins to "see" the patterns that emerge from the data sets. Often repeated themes become major chunks of meaning, while less frequently repeated ideas form a sub-set of minor themes. Very infrequent or unique ideas that are expressed by a single participant or that are unique to a very small number of participants may be treated as outliers. However, when finding indicators of growth in conceptual development is the research goal, outliers may also indicate the leading edge of conceptual development so these are important to retain and report. Common themes and outliers together form the outcome space of the data.

The following description provides an example of this recursive and staged process of coding:

A detailed analysis followed, where I re-evaluated and compared each response using an "iterative reading and re-reading of transcripts to establish similarities and differences in the responses made" (Entwistle \& Marton, 1994, p. 166). During the re-reading, I highlighted blocks of text with similar conceptions. I then collated identified conceptions into a new document and organized them using charts to create an initial set of categories. Once this step was complete, I continued sorting and analyzing to uncover any characteristics that explained the conceptions related to the focal concept and the shared understanding documented by the pre-service teachers. This process also led to the uncovering of any conceptions that might have changed over the course of the pre-service Social Studies course. This allowed for even greater deconstruction of the utterances, where the conceptions of each participant were more accurately placed in their respective categories (Goh, 2013). Finally, I selected specific comments to provide quotations that represented the pre-service teachers' discerned conceptions of the central concept at the beginning and end of the Social Studies course as well as the changes that occurred in their thinking. (Straub, 2020) 


\section{Ml Macrothink}

Journal of Studies in Education

ISSN 2162-6952

2021, Vol. 11, No. 2

This example shows the iterative and recursive methodology that is characteristic of phenomenography and shows clearly how phenomenographic researchers must follow the data, rather than trying to fit the data into pre-existing frameworks.

\subsubsection{Determine the global meaning of the data}

According to Marton and Pong (2005) individuals hold meaning in both structural and global ways where "structurally, different people will notice, prioritize and place value on different aspects of an experience" (p. 888). Global meaning of a participant's statements focuses the researcher on determining the overall meaning of the statements made by each participant in the "broader context of his or her values, needs and perspectives" (p. 888). Global meaning analysis requires little interpretation by the researcher. By isolating the global meaning of each utterance, the researcher can consider the uniqueness of individual participants and the experiences each one brings to the study. By extension, global meaning could also be inferred from the context and life experiences that the participant brings to the study.

\subsubsection{Consider structural aspects or features to support the global meaning of experiences}

Natural environments like the pre-service Social Studies class are useful contexts "for discovering how participants construct their own meaning of events or situations" (Suter, 2012, p. 344 ). The semantic meaning that study participants make of (or see in) their own experiences and the meaning that researchers attribute to the statements made by participants make up the structural elements (also called referential elements) of the participant's input (Gunton, Bruce, \& Stoodley, 2012). The researcher's semantic meaning making also includes the researcher's thoughts about the process of uncovering the participant's meaning as each participant speaks or writes about personal experiences and what they mean. Structural meanings (also called aspects or elements) include the conceptions of experience that are at the margins of the group's experience or that are absent from most or all of the conceptions expressed by group members.

Researchers must recognize that identifying structural elements that are absent from individual and group utterances take time to recognize by their nature. That is, the researcher is required to see what is not there but that might be expected to be. The experienced researcher will recognize structural meanings at the margins of experience (e.g., those that are sparsely included or mentioned frequently but by only one participant) in the outcome space (i.e., the range that exists of all of the conceptions uncovered). For example, if one participant mentioned a concept repeatedly, the researcher would consider the concept to be important, but if that same concept was mentioned by only one participant or by a small number of participants in a large pool of participants, the concept then appears on the fringe of the outcome space. This type of fringe utterance would cause the researcher to question why the concept was excluded from most utterances and what this structural meaning entails in the body of data.

\subsubsection{Develop categories}




\section{Mll Macrothink}

Journal of Studies in Education

ISSN 2162-6952

2021, Vol. 11, No. 2

With data obtained through phenomenographic research, the researcher will analyze and reanalyze the data set until common themes in the data begin to emerge. Once the commonality is uncovered in the data, further evidence of the theme will be highlighted by the researcher, and once the researcher determines the strength of the common theme in the data, a data category can be named. For example, in relation to exploring pre-service teachers' conceptual frames about citizenship, recent research (Straub, 2020) highlighted that pre-service teachers held common conceptions of citizenship related to five themes, which formed the main categories of data, including: 1) Citizenship as Place; 2) Legal Dimension of Citizenship; 3) Socio-Cultural Dimensions of Citizenship; 4) Civic Engagement; and, 5) Civic Orientations. The evolution of the researcher's ability to see categories of meaning in the data is critical as it forms a gateway into analysis that can lead the researcher to determine frequency of the category and to consider relative strength of each category of meaning and connections among the categories (e.g., Do all participants who saw themselves as belonging to a particular place, have lower or higher levels of civic engagement than participants who do not define their citizenship by location?). Examination of connections across categories opens data analysis to uncover the deep meaning of individual utterances in the data set.

Gunton, Bruce, and Stoodley (2012) maintained that data analysis involves distinguishing the qualitative variation between the different experiences of the phenomenon presented by the participants. Limberg (2000) highlighted that after reading and in-depth familiarization with the transcripts, the researcher begins to uncover the unique forms of experience. These are noted and used to map out categories of phenomena. Once categories are established, the focus begins to shift from the individual's perspective of the experience to the collective experience shared by multiple participants. It is important to note that early versions of categories are not fixed; they can be adjusted, if necessary, to reflect the "collective consciousness" (Guton, Bruce, \& Stoodley, 2012, p. 14). This is the iterative process that permeates this methodology. The identified categories include specific aspects that communicate the meaning of the category - such as referential aspects - as well as structural aspects. These identify the main focus in each experience. Structural aspects include statements that represent conceptions of experience that are at "the margin" (Marton \& Booth, 1997, p. 122) - at the outer edges of the experience or absent in the account. Åkerlind (2008) presented criteria for such outcome spaces as categories that are distinctive, logically related, and few in number. The variations that appear from these experiential accounts are then examined to uncover the ways participants experience the phenomenon (Marton \& Booth, 1997).

\subsubsection{Establish relationships among categories}

Establishing relationships across the emergent categories in a data set is, as stated earlier, critical to allowing the researcher the ability to interrogate the data for deep meaning. This is essentially a correlational (not a causal) exercise. The researcher asks questions of the data set by speculating about possible correlations in the form of questions framed as, "Do participants who showed $\mathrm{X}$, have higher tendencies toward Y?" Such questions allow the phenomenographic researcher to step back from the group data and look at individual trends, before once again considering the strength of the trends in the group. This constant move back and forth between the group (the whole) and the individual (the part) data is critical to ensure 
accurate interpretation of the data and to allow the researcher to state the significance of the finding in suitable proportion to the validity of the findings across similar populations and circumstances.

Once the completed data collection has been organized, tentative categories emerge. Kinnunen and Simon (2012) discussed how they began by selecting two rich texts and started "fracturing the text" (p. 210) by reading it sentence by sentence. They highlighted questions like: "What is the essence of this sentence?" and "Which concept would best capture the essence of the theme or idea described in the sentence?" These reflective questions allow the comparison of each sentence - and the concepts within - to uncover similarities and differences. This process condenses and abstracts the data, which allows for what can be characterized as a "concrete outcome" (p. 210). Each outcome can be linked to a specific data code. According to Saldaña (2008), "a code in qualitative inquiry is most often a word or short phrase that symbolically assigns a summative, salient, essence-capturing, and/or evocative attribute for a portion of language-based or visual data" (p. 3). Saldaña stated that

the portion of data to be coded during First Cycle coding processes can range in magnitude from a single word to a full sentence to an entire page of text to a stream of moving images. In Second Cycle coding processes, the portions coded can be the exact same units, longer passages of text, and even a reconfiguration of the codes themselves developed thus far. (p. 3)

The coding process involves revising and re-coding data recursively as the researcher tries to determine the global meaning of each statement within the interviews.

The iterative and recursive nature of the coding process can be summarized as a series of steps, as follows:

- focusing on the meaning of a category or its parts;

- considering the what or how of the phenomenon;

- $\quad$ using similarities and differences within and between categories;

- seeking to resolve information in transcripts that does not fit into any category; and,

- understanding that changing one category may contain implications for other categories. (adapted from Åkerlind, 2008)

\subsubsection{Report meaning/outcome space}

Reporting meaning in phenomenographic research is about asking, "What are the variations that exist between the conceptions?" These different categories, when perceived as a whole, identify the essence of the phenomenon (Limberg, 2008; Marton \& Booth, 1997). Interpreting and reporting on the meaning of the data is about answering the question "So what?". After careful analysis and re-analysis of the data once coding practices begin to yield commonalities and themes and data categories begin to emerge, the researcher must begin to address the meaning of the data. Making meaning of the findings of research is essential to relevance and to the mobilization of new knowledge. Researchers have many avenues of dissemination for their research findings, including conferences, theses, technical reports, journal articles, 
published books, magazine articles, and workshops, to name the most commonly used methods of dissemination. Reporting meaning can also lead researchers to funding opportunities which open doors to the final stage of phenomenography.

\subsubsection{Identify new research questions}

Categories of descriptions are the outcome space variations among the ways of experiencing the reality of the same phenomenon (Marton \& Pong, 2005). This process is not finite. While the information may be reported on at this time, it may also lead and motivate the researcher to continue investigating as new research questions develop.

\section{Limitations}

All studies have limitations. Limitations may evolve because of many research realities such as funding limits, time limits, geographic realities, participant characteristics, and unforeseen methodological issues, among many other possibilities. It is because of such limitations and therefore the limits of a researcher's ability to claim new knowledge in absolute terms (e. g., "because this worked like this here, it will work like this everywhere"), there is always a need for good researchers to end one study by starting another to explore the boundaries of their outcome space. Researchers do this by asking new and related research questions that frame what we now know in relation to what we don't yet know. In this sense, the limitations of one study become the foundations for a new study.

\section{Summary}

Phenomenography is a complex yet adaptable research paradigm. This paper has attempted to develop further understanding of this research approach, using examples to illuminate several of the stages of phenomemography. By providing a model of the process of phenomenography (Figure 1) and a breakdown of its static and recursive phases (Table 1), the authors have tried to make the power and accessibility of this approach to qualitative research evident to other researchers.

\section{References}

Åkerlind, G. (2005). Variation and commonality in phenomenographic research methods. Higher Education Research and Development, 24(4), 321-334. https://doi.org/10.1080/07294360500284672

Åkerlind, G. (2008). An Academic Perspective on Research and Being a Researcher: An Integration of the Literature.' Studies in Higher Education, 33 (1)17-31. https://doi.org/10.1080/03075070701794775

Anderberg, E., Svensson, L., Alvegård, C., \& Johansson, T. (2008). The epistemological role of language use in learning: A phenomenographic intentional-expressive approach. Educational Research Review, 3(1), 14-29. https://doi.org/10.1016/j.edurev.2007.10.003

Blummer, B., Watulak, S. L. \& Kenton, J. (2013). The research experience for education graduate students: A phenomenographic study, Internet Reference Services Quarterly, 17(3-4), 117-146. 


\section{MlMacrothink}

Journal of Studies in Education

ISSN 2162-6952

2021, Vol. 11, No. 2

Boon, J., \& Webber, S. (2007). A phenomenographic study of English faculty's conceptions of information literacy. Journal of Documentation, 63(2), 204-228. https://doi.org/10.1108/00220410710737187

Booth, S. (2008, May). Researching learning in networked learning: Phenomenography and variation theory as empirical and theoretical approaches. In V. Hodgson, C. Jones, T. Kargidis, D. McConnnell, S. Retalis, D. Stamatis, \& M. Zenios (Eds.) Proceedings of the 6th International Conference on Networked Learning (pp. 450-455), Halikdiki, Greece.

Bruce, C., Buckingham, L., Hynd, J., McMahon, C., Roggenkamp, M., \& Stoodley, I. (2004). Ways of experiencing the act of learning to program: A phenomenographic study of introductory programming students at university. Journal of Information Technology Education, 3, 143-160. https://doi.org/10.28945/294

Bruce, C. S. (1999). Phenomenography: Opening a new territory for LIS research. New Review of Library and Information Research, 5, 31-48.

Case, J. \& Light, G. (2011). Emerging methodologies in engineering education research. Journal of Engineering Education, 100(1), 186-210. https://doi.org/10.1002/j.21689830.2011.tb00008.x

Creswell, J. W. (2009). Research Design: Qualitative, Quantitative, and Mixed Methods Approaches (3rd ed.). Sage.

Crowe, A., Dirks, C., \& Wenderoth, M. P. (2008). Biology in bloom: Implementing Bloom's taxonomy to enhance student learning in biology. CBE Life Sciences Education, 7(4), 368-381. https://doi.org/10.1187/cbe.08-05-0024

Dahlin, B. (1999). Ways of coming to understand: Metacognitive awareness among first-year university students. Scandinavian Journal of Educational Research,43(2), 191-208. https://doi.org/10.1080/0031383990430205

Denzin, N. K. (1989). The research act: A theoretical introduction to sociological methods (3rd ed.). Aldine.

Driver, R. \& Easley, J. (1978). Pupils and paradigms: A review of literature related to concept development in adolescent science students. Studies in Science Education, 1, 61-84. https://doi.org/10.1080/03057267808559857

Entwistle, N. \& Marton, F. (1994). Knowledge objects: Understandings constituted through intensive academic study. British Journal of Educational Psychology, 64(1), 161-178. https://doi.org/10.1111/j.2044-8279.1994.tb01092.x

Feldon, D., \& Tofel-Grehl, C. (2018). Phenomenography as a Foundation for Mixed Models Research. The American Behavioral Scientist (Beverly Hills),62(7), 887-899. https://doi.org/10.1177/0002764218772640

Goh, P. S. (2013). Conceptions of competency: A phenomenographic investigation of beginning teachers in Malaysia. The Qualitative Report, 18(20), 1-16. 
Gunton, L., Bruce, C., \& Stoodley, I. (2012). Experiencing religious information literacy: Informed learning in church communities. The Australian Library Journal, 61(2), 119-132. https://doi.org/10.1080/00049670.2012.10722681

Hella, E., \& Wright, A. (2009). Learning 'about' and 'from' religion: Phenomenography, the variation theory of learning and religious education in Finland and the UK. British Journal of Religious Education, 31(1), 53-64. https://doi.org/10.1080/01416200802560047

Hughes, A. S., \& Sears, A. (2004). Situated learning and anchored instruction as vehicles for social education. In A. Sears \& I. Wright (Eds.), Challenges and prospects for Canadian social studies (pp. 259-227). Pacific Educational Press.

Kinnunen, P. \& Simon, B. (2012). Phenomenography and grounded theory as research methods in computing education research field. Computer Science Education, 22(2), 199-218. https://doi.org/10.1080/08993408.2012.692928

Lam, H. C. (2013). On generalization and variation theory. Scandinavian Journal of Educational Research, 57(4), 343-356. https://doi.org/10.1080/00313831.2012.656277

Limberg, L. (2000). Phenomenography: A relational approach to research on information needs, seeking and use. The New Review of Information Behaviour Research, 1(January), 51-67.

Limberg, L. (2008). Phenomenography. In L. Given (Ed.), The SAGE encyclopedia of qualitative research methods. (pp. 612-615). Sage.

Marton, F. (1981). Phenomenography - Describing conceptions of the world around us. Instr Sci 10, 177-200. https://doi.org/10.1007/BF00132516

Marton, F. (1992). Phenomenography and the "art of teaching all things to all men". International Journal of Qualitative Studies in Education, 5(3), 253-257.

Marton, F. \& Booth, S. (1997). Learning and awareness. Lawrence Erlbaum.

Marton, F. \& Pong, W. Y. (2005). On the unit of description in phenomenography. Higher Education Research and Development, 24(4), 335-348. https://doi.org/10.1080/07294360500284706

Marton, F., Runesson, U., \& Tsui, A. B. M. (2004). The space of learning. Classroom discourse and the space of learning. Lawrence Erlbaum. https://doi.org/10.4324/9781410609762

Maybee, C. (2007). Understanding our student learners. Reference Services Review, 35(3), 452462. https://doi.org/10.1108/00907320710774319

Newton, G. \& Martin, E. (2013). Blooming, solo taxonomy, and phenomenography as assessment strategies in undergraduate science education. Journal of College Science Teaching, 43(2), 78-90. https://doi.org/10.2505/4/jcst13_043_02_78

Ornek, F. (2008). An overview of a theoretical framework of phenomenography in qualitative education research: An example from physics education research. Asia-Pacific Forum on Science Learning And Teaching, 9(2), 1-14. 


\section{Macrothink}

Patton, M. Q. (2002). Two decades of developments in qualitative inquiry: A personal, experiential perspective. Qualitative Social Work, 1(3), 261-283. https://doi.org/10.1177/1473325002001003636

Polat, B. (2013). Experiencing language: Phenomenography and second language acquisition. Language Awareness, 22(2), 111-125. https://doi.org/10.1080/09658416.2012.658811

Prosser, M. (1994). Some experiences of using phenomenographic research methodology in the context of research in teaching and learning. In Bowden, J, Walsh, E. (Eds.) Phenomenographic Research: Variations in Method. EQARD, RMIT, 31-43.

Reid, A. \& Petocz, P. (2002). Students' conceptions of statistics: A phenomenographic study. Journal of Statistics Education, 10(2). https://doi.org/10.1080/10691898.2002.11910662

Saldaña, J. (2008). The coding manual for qualitative researchers. Sage.

Sjöström, B. \& Dahlgren, L. O. (2002). Applying phenomenography in nursing research. Journal of Advanced Nursing, 40(3), 339-345. https://doi.org/10.1046/j.13652648.2002.02375.x

Straub, J. (2020). Pre-service teachers' understanding of citizenship [Doctoral dissertation, University of New Brunswick]. https://unbscholar.lib.unb.ca/islandora/object/unbscholar\%3A10138/datastream/PDF/view

Suter, W. N. (2012). Qualitative data, analysis, and design. In Introduction to educational research: A critical thinking approach (pp. 342-386). Sage. https://doi.org/10.4135/9781483384443.n12

Trigwell, K., Prosser, M., \& Ginns, P. (2005). Phenomenographic pedagogy and a revised approach to teaching inventory. Higher Education Research \& Development, 24(4), 349-360. https://doi.org/10.1080/07294360500284730

Trigwell, K. \& Yasukawa, K. (1999). Learning in a graduate attributes-based engineering course. HERDSA Annual International Conference, Melbourne, Australia. http://www.herdsa.org.au/wpcontent/uploads/conference/1999/pdf/Trigwell. PDF.

Yates, C., Partridge, H., \& Bruce, C. (2009). Learning wellness: How ageing Australians experience health information literacy. The Australian Library Journal, 58(3), 269-285. https://doi.org/10.1080/00049670.2009.10735905 